\title{
Correction to: Inflammatory markers before and after farrowing in healthy sows and in sows affected with postpartum dysgalactia syndrome
}

\author{
M. Kaiser ${ }^{1^{*}}$, M. Jacobson ${ }^{2}$, P. H. Andersen ${ }^{2}$, P. Bækbo ${ }^{3}$, J. J. Cerón ${ }^{4}$, J. Dahl$^{5}$, D. Escribano ${ }^{4}$ and S. Jacobsen ${ }^{1}$
}

\section{Correction}

The original article [1] contains an error whereby the caption in Figure 8 is incorrect; the correct caption can be seen ahead alongside its respective image.

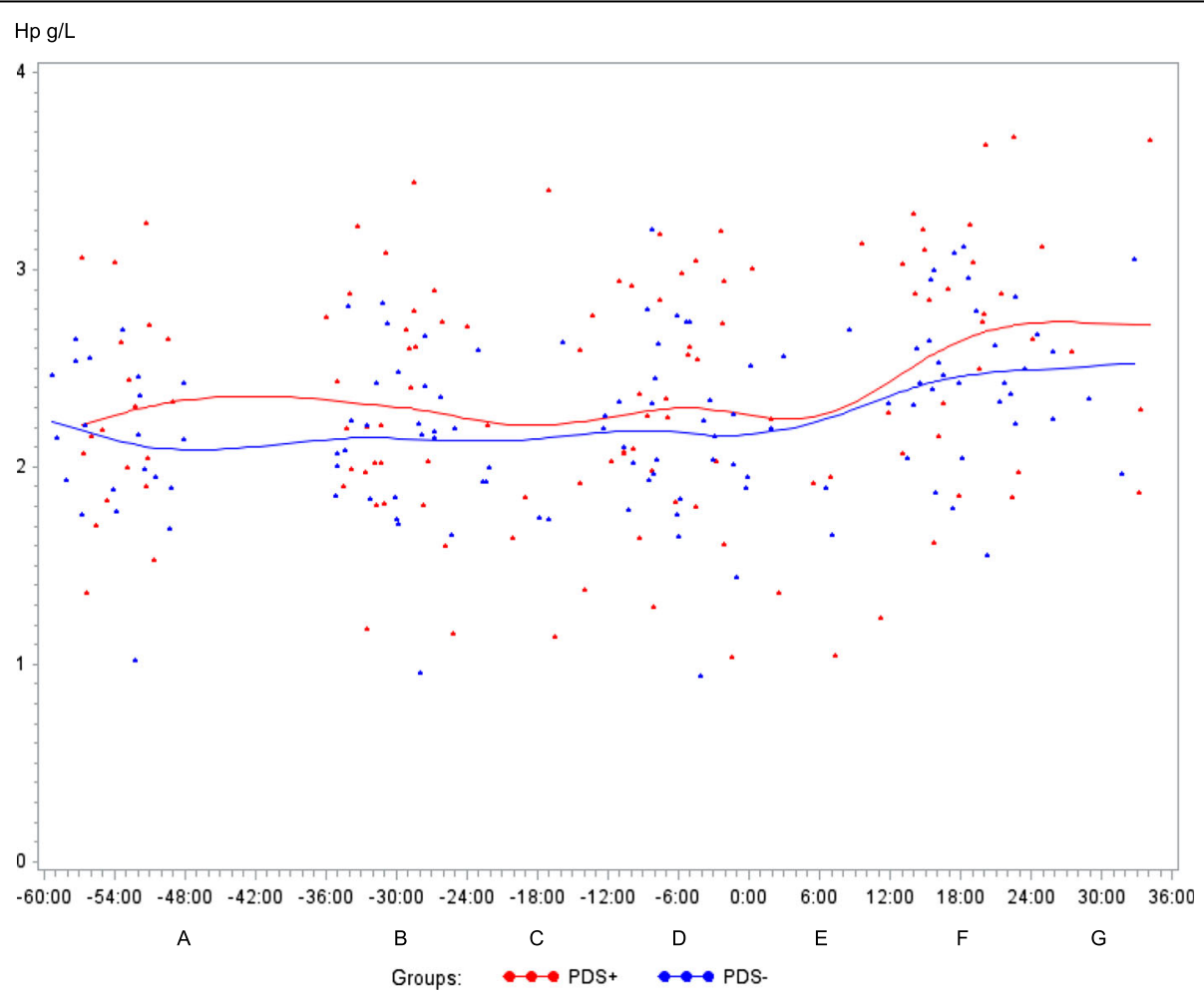

Fig. 8 Haptoglobin $(\mathrm{Hp})$ concentration $(\mathrm{g} / \mathrm{L})$ in sows with postpartum dysgalactia syndrome (PDS+, red) and healthy sows (PDS-, blue) sampled from $60 \mathrm{~h}$ before until $36 \mathrm{~h}$ after parturition (time interval $\mathrm{A}-\mathrm{G}$ ). Each dot represents the exact sample time of each observation relative to the exact birth of the first piglet $(0 \mathrm{~h})$. The lines show the mean value

\section{* Correspondence: kaiser@sund.ku.dk}

${ }^{1}$ Department of Veterinary Clinical Sciences, Faculty of Health and Medical

Sciences, Copenhagen University, Højbakkegård Alle 5, 2630 Taastrup,

Denmark 


\section{Author details}

${ }^{1}$ Department of Veterinary Clinical Sciences, Faculty of Health and Medical Sciences, Copenhagen University, Højbakkegård Alle 5, 2630 Taastrup, Denmark. ${ }^{2}$ Department of Clinical Sciences, Faculty of Veterinary Medicine and Animal Science, Swedish University of Agricultural Sciences, p.o. Box 7054, SE-750 07 Uppsala, Sweden. ${ }^{3}$ SEGES, Danish Pig Research Center, Danish Agriculture \& Food Council, Agro Food Park 15, 8200 Aarhus N, Denmark. ${ }^{4}$ Department of Animal Medicine and Surgery, Regional "Campus of Excellence Mare Nostrum", University of Murcia, 30100 Espinardo, Murcia, Spain. ${ }^{5}$ Danish Agriculture and Food Council, Axelborg, Axeltorv 3, 1709 Copenhagen V, Denmark.

Published online: 01 June 2018

Reference

1. Kaiser $\mathrm{M}$, et al. Inflammatory markers before and after farrowing in healthy sows and in sows affected with postpartum dysgalactia syndrome. BMC Vet Res. 2018;14:83. 